\title{
Efficacy of erbium-doped yttrium aluminum garnet laser with casein phosphopeptide amorphous calcium phosphate with and without fluoride for remineralization of white spot lesions around orthodontic brackets
}

\author{
Sogra Yassaei ${ }^{1}$, Hossein Aghili $^{1}$, Neda Shahraki ${ }^{2}$, Isa Safari ${ }^{1}$
}

Correspondence: Dr. Isa Safari

'Department of Orthodontics, Faculty of Dentistry, Shahid Sadoughi University of Medical Sciences, Yazd, Iran,

E-mail: isasafari1365@gmail.com

${ }^{2}$ Department of Orthodontics, Faculty of Dentistry, Zahedan University of Medical Sciences, Zahedan, Iran

\section{ABSTRACT}

Objective: This study aimed to assess the efficacy of erbium-doped yttrium aluminum garnet (Er:YAG) laser, pastes containing casein phosphopeptide amorphous calcium phosphate (CPP-ACP) with and without fluoride and their combination for prevention of white spot lesions in the enamel. Materials and Methods: This in vitro experimental study was conducted on 90 extracted sound premolars. The teeth were then randomly divided into six groups of 15: (1) Control, (2) laser, (3) CPP-ACP with fluoride (GC MI Paste, Recaldent ${ }^{\mathrm{TM}} 900 \mathrm{ppm}$ as NaF), (4) CPP-ACP without fluoride (GC Tooth Mousse Recaldent ${ }^{\mathrm{TM}}$ ), (5) laser + CPP-ACP with fluoride, and (6) laser + CPP-ACP without fluoride. In each group, enamel surface was exposed to the remineralizing agent. The teeth were then subjected to $\mathrm{pH}$ cycling for 14 days. The teeth were then sectioned, polished, and underwent cross-sectional microhardness testing at 20-160 $\mu$ depth quantitatively. Using the Simpson's rule, the amount of mineral loss was calculated in each group. Statistical Analysis Used: ANOVA was used for the comparisons, and Tukey's test was applied for pairwise comparisons. Results: The highest mean volume percentage of microhardness at 20-60 $\mu$ depth belonged to the group laser + CPP-ACP with fluoride and the lowest belonged to the control group $(P=0.001)$. The differences were not significant at $80-120 \mu$ depth $(P>0.05)$. These finding are confirmed according to $\Delta \mathrm{Z}$ (mineral loss). Conclusion: Based on these results, Er: YAG laser was able to decrease demineralization and was a potential alternative to preventive dentistry and was more effective when combined with CPP-ACP products.

Key words: Casein phosphopeptide amorphous calcium phosphate, erbium-doped yttrium aluminum garnet laser, white spot lesion

\section{INTRODUCTION}

Enamel demineralization and formation of white spot lesions (WSLs) around orthodontic brackets are

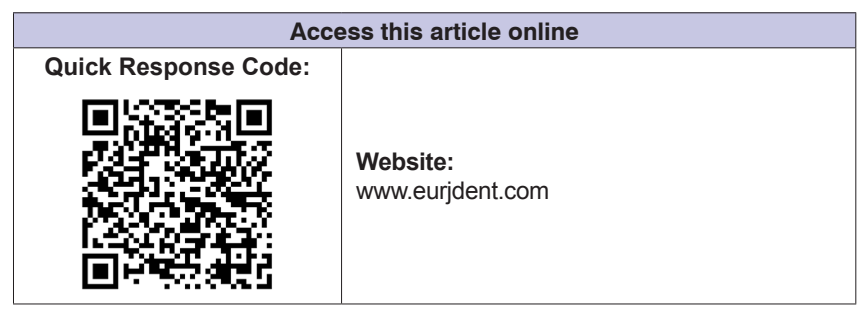

This is an open access journal, and articles are distributed under the terms of the Creative Commons Attribution-NonCommercial-ShareAlike 4.0 License, which allows others to remix, tweak, and build upon the work non-commercially, as long as appropriate credit is given and the new creations are licensed under the identical terms.

For reprints contact: reprints@medknow.com

How to cite this article: Yassaei S, Aghili H, Shahraki N, Safari I.
Efficacy of erbium-doped yttrium aluminum garnet laser with casein
phosphopeptide amorphous calcium phosphate with and without
fluoride for remineralization of white spot lesions around orthodontic
brackets. Eur J Dent 2018;12:210-6.
DOI: $10.4103 /$ ejd.ejd_265_17 
a common problem, especially in patients with poor oral hygiene. ${ }^{[1,2]}$ The prevalence of WSLs is 50\%-95\% in patients using fixed orthodontic appliances. ${ }^{[3,4]}$

Early detection and treatment of WSLs during orthodontic treatment is highly important because these lesions are reversible. Casein phosphopeptide amorphous calcium phosphate (CPP-ACP) products were recently introduced for caries prevention and remineralization of demineralized enamel. ${ }^{[5,6]} \mathrm{CPP}-\mathrm{ACP}$ is applied on the tooth surface and dental plaque and when exposed to acid, it releases calcium and phosphate ions. Subsequently, the concentration of calcium and phosphate ions increases in the oral cavity and thus, they deposit on the tooth surface, prevent caries, and enhance remineralization. ${ }^{[7]}$ Evidence shows that CPP-ACP compounds can decrease demineralization and increase remineralization of enamel in vivo and in vitro. ${ }^{[8-10]}$ Iijima et al. ${ }^{[11]}$ in their clinical study showed that the addition of $18.8 \mathrm{mg}$ CPP-ACP to sugar-free gums increased the enamel resistance to demineralization and enhanced remineralization. CPP-ACP is also added to some fluoride compounds, and it has been claimed that these products have higher potential for enamel remineralization due to fluoride release. ${ }^{[12-14]}$ Guotoa et al..$^{[15]}$ assessed the efficacy of tooth mousse (GC, Tokyo, Japan)-containing CPP-ACP for enamel remineralization using circulatory polarized image and concluded that it can decrease the size of demineralized lesions and increase enamel remineralization; its combination with fluoride further increases its remineralizing efficacy.

Recently, laser irradiation was suggested for caries prevention. $\mathrm{CO}_{2}$, erbium, and erbium-doped yttrium aluminum garnet (Er:YAG) lasers are effective for caries prevention. ${ }^{[16-21]}$ These lasers are highly absorbed by water and hydroxyapatite crystals and can change their crystalline structure and increase their resistance to demineralization. ${ }^{[19]}$

Jeng feng liu et al..$^{[22]}$ evaluated the efficacy of Er:YAG laser for caries prevention and concluded that this laser can be an efficient tool for the prevention of enamel demineralization. Efficacy of remineralizing agents and laser has been previously evaluated but studies on their synergistic effect on caries prevention are limited. Thus, this study aimed to assess the efficacy of Er:YAG laser irradiation along with (CPP-ACP) with and without fluoride for remineralization of WSLs in vitro.

\section{MATERIALS AND METHODS}

This in vitro study was conducted on 90 premolar teeth extracted for orthodontic reasons. The teeth were rinsed with saline and immersed in $0.1 \%$ thymol solution. Premolar teeth with abnormal anatomy, cracks, or caries were excluded from the study. The teeth were cleaned with nonfluoridated pumice paste and rubber cup and dried for $15 \mathrm{~s}$.

To prevent demineralization, the entire tooth surface, except for a rectangular-shaped window measuring $5 \mathrm{~mm} \times 6 \mathrm{~mm}$, was coated with acid-resistant nail varnish (Revlon, New York, NY, USA). The teeth were then randomly divided into six groups $(n=15)$ as follows:

- G1 or control group: The teeth underwent $\mathrm{pH}$ cycling with no extra intervention

- $p H$-cycling process: The teeth were immersed in a demineralizing agent $(2.0 \mathrm{mmol} / \mathrm{L}$ calcium, $2.0 \mathrm{mmol} / \mathrm{L}$ phosphate, and $0.03 \mathrm{mg}$ fluoride in $75 \mathrm{mmol} / \mathrm{L}$ acetate buffer with a $\mathrm{pH}$ of 4.3 ) manufactured in School of Chemistry of Yazd University for $3 \mathrm{~h}$ daily and were then immersed in a remineralizing agent $(1.5 \mathrm{mmol} / \mathrm{L}$ calcium, $0.9 \mathrm{mmol} / \mathrm{L}$ phosphate, and $150 \mathrm{mmol} / \mathrm{L} \mathrm{KCL}$ in $20 \mathrm{mmol} / \mathrm{L}$ cacodylate buffer with a $\mathrm{pH}$ of 7.4) for $20 \mathrm{~h}$. This process was continued for 10 days, and then, the teeth were immersed in the remineralizing agent at $37^{\circ} \mathrm{C}$ for two more days. During the time intervals between immersions and after completion of $\mathrm{pH}$ cycling, the teeth were rinsed with saline for $10 \mathrm{~s}$ and dried with paper towel. Both solutions were refreshed after every five cycles, and $1 \%$ thymol was added to prevent the growth of microorganisms

- G2 or Er: YAG laser: This group was only subjected to laser radiation

- G3 or CPP-ACP with fluoride (GC MI Paste Plus, Recaldent ${ }^{\mathrm{TM}} 900$ ppm as NaF, GC Corporation Tokyo, Japan): In this group, after drying the enamel, the respective area was exposed to MI Paste Plus with 900 ppm fluoride (CPP-ACP technology, School of Dental Science, Melbourne, Australia) and rinsed with saline after $5 \mathrm{~min}$

- G4 or CPP-ACP without fluoride (GC Tooth Mousse, Recaldent ${ }^{\mathrm{TM}}$ GC Corporation Tokyo, Japan): After drying the enamel, the respective area was exposed to GC Tooth Mousse (CPP-ACP technology, School of Dental Science, Melbourne, Australia) and rinsed with saline after $5 \mathrm{~min}$

- G5 or Er: YAG laser + CPP-ACP with fluoride: In this group, the respective area was laser irradiated and then MI Paste Plus was applied 
- G6 or ER:YAG laser + CPP-ACP without fluoride: In this group, the respective site was laser irradiated and then GC Tooth Mousse was applied.

In the laser groups (G2, G5, and G6), the teeth were subjected to Er:YAG laser (KEY Laser 3+, Kavo Dental Corp., Biberach, Germany) irradiation with $2.94 \mu \mathrm{m}$ wavelength, $80 \mathrm{~mJ}$ energy, $4 \mathrm{~Hz}$ frequency and $80 \mathrm{~mJ}$ energy per pulse for $10 \mathrm{~s}$ under water and air spray with 2060 hand piece (Kavo Dental Corp., Biberach, Germany) at $20 \mathrm{~mm}$ distance from the surface in nonfocal mode and perpendicular to the tooth surface with a swiping motion. Next, the teeth in all groups were subjected to $\mathrm{pH}$ cycling to artificially create WSLs. Next, the teeth were sectioned at the middle of the exposed enamel surface by a cutting saw and each section was mounted in polyester resin.

Considering the need for polishing of the surface before microhardness testing, the slices were first polished by Soflex polishing discs (3M ESPE, St. Paul, MN, USA) serially from coarse to fine under water coolant and then subjected to further polishing with silicon carbide rotary discs starting from 6000 grit to the finest grit under water coolant.

The hardness profile was then measured using a hardness tester (FM-700 type D, Future-Tech, Kawasaki, Japan) by a Knoop diamond indenter with $10 \mathrm{~g}$ load applied for $5 \mathrm{~s}$ at 20,40,60, 80, 100, 120, 140, and $160 \mu \mathrm{m}$ distances from the external border of the enamel. To increase accuracy, hardness was measured at three points at each depth, and then, the Knoop hardness number $(\mathrm{KHN})$ was converted to volume percentage of mineral content using the formula below: ${ }^{[23]}$

Vol $\%$ mineral $=4.3(\mathrm{KHN})^{1 / 2}+11.3$

To obtain the relative mineral loss $(\Delta \mathrm{Z})$, the volume percentage values were graphed against distance and using Simpson's rule for calculation of the integral of area under the curve, the integral of mineral loss for each group was calculated such that first, the integral of sound enamel and then the integral of affected enamel were calculated and subtracted to obtain the amount of mineral loss.

Data were analyzed using PASW version 18 (SPSS,Chicago,IL). ANOVA was used for the comparisons, and Tukey's test was applied for pairwise comparisons.

\section{RESULTS}

ANOVA found a significant difference in the mean hardness value of different groups at 20-60 $\mu$ depths $[P<0.0001$, Table 1$]$.

According to Table 1, the mean volume percentage of hardness at $20 \mu$ depth in different groups was in the range of 54.85-94.79. At $20 \mu$ depth, the highest volume percentage of hardness belonged to the laser + CPP-ACP with fluoride group $(83.53 \pm 5.59)$ while the lowest was noted in the control group $(62.78 \pm 5.23)(P=0.001)$. The same trend was observed at 40 and $60 \mu$ depths. ANOVA showed a significant difference in the mean hardness value of the groups at $20-60 \mu$ depths $(P=0.001)$. The differences were not significant at 80-120 $\mu$ depth $(P>0.05)$ [Table 1 and Figure 1].

Table 2 shows the mean relative mineral loss $(\Delta \mathrm{Z})$ in different groups. The highest mineral loss was noted in the control group (1902.26 \pm 141.38$)$ while the lowest belonged to CPP-ACP with $\mathrm{F}+$ laser group (900.49 \pm 164.29$)$. ANOVA test showed a significant difference between relative mineral loss $(\Delta \mathrm{Z})$ in six groups $(P=0.001)$.

Table 3 shows the results of Tukey's test. According to Table 3, laser and CPP-ACP without fluoride + laser groups were not significantly different in terms of $\triangle \mathrm{Z}$. In addition, laser and CPP-ACP with fluoride groups were similar $(P>0.05)$. CPP-ACP

\begin{tabular}{|c|c|c|c|c|c|c|c|c|}
\hline \multirow[t]{2}{*}{ Groups } & \multicolumn{8}{|c|}{ Mean $\pm S D$} \\
\hline & 20 depth & 40 depth & 60 depth & 80 depth & 100 depth & 120 depth & 140 depth & 160 depth \\
\hline CPP-ACP with fluoride & $72.20 \pm 7.33$ & $74.97 \pm 6.67$ & $78.11 \pm 4.26$ & $91.44 \pm 3.29$ & $89.86 \pm 5.73$ & $92.41 \pm 3.88$ & $91.88 \pm 2.62$ & $93.80 \pm 3.80$ \\
\hline Laser & $75.51 \pm 4.44$ & $78.78 \pm 3.56$ & $79.70 \pm 4.31$ & $89.58 \pm 4.35$ & $91.06 \pm 3.10$ & $90.80 \pm 3.06$ & $92.42 \pm 3.52$ & $92.36 \pm 4.26$ \\
\hline CPP-ACP without fluoride & $70.47 \pm 4.37$ & $72.20 \pm 4.65$ & $77.14 \pm 4.27$ & $89.72 \pm 4.63$ & $90.19 \pm 3.75$ & $90.70 \pm 3.35$ & $91.29 \pm 4.30$ & $92.56 \pm 3.96$ \\
\hline CPP-ACP without fluoride + laser & $79.57 \pm 5.65$ & $80.14 \pm 3.11$ & $80.45 \pm 5.41$ & $89.01 \pm 5.55$ & $91.86 \pm 4.58$ & $92.31 \pm 4.06$ & $91.50 \pm 4.38$ & $91.99 \pm 4.59$ \\
\hline CPP-ACP with fluoride + laser & $83.53 \pm 5.59$ & $83.50 \pm 6.47$ & $82.93 \pm 8.92$ & $91.49 \pm 3.60$ & $91.45 \pm 3.57$ & $91.82 \pm 4.22$ & $91.43 \pm 3.19$ & $92.32 \pm 3.97$ \\
\hline Control & $62.78 \pm 5.23$ & $61.61 \pm 3.86$ & $63.25 \pm 6.31$ & $88.90 \pm 7.75$ & $91.46 \pm 4.16$ & $90.91 \pm 4.15$ & $92.14 \pm 4.15$ & $91.81 \pm 4.93$ \\
\hline Significant & $0.0001^{*}$ & $0.0001^{*}$ & $0.0001^{*}$ & 0.597 & 0.762 & 0.676 & 0.958 & 0.841 \\
\hline
\end{tabular}


Yassaei, et al:: Efficacy of Er:YAG and CPP-ACP $\pm F$ on white spot

\begin{tabular}{llc} 
Table 2: Mean mineral loss $(\Delta \mathbf{Z})$ & values of the groups \\
\hline Groups & $\boldsymbol{n}$ & Mean \pm SD \\
\hline Control & 15 & $1902.26 \pm 141.38$ \\
CPP-ACP without fluoride & 15 & $1377.87 \pm 155.97$ \\
CPP-ACP with fluoride & 15 & $1268.14 \pm 176.24$ \\
Laser & 15 & $1135.64 \pm 109.93$ \\
CPP-ACP without fluoride + laser & 15 & $1066.11 \pm 134.02$ \\
CPP-ACP with fluoride + laser & 15 & $900.49 \pm 164.29$ \\
Significant & & 0.000
\end{tabular}

The mean difference is significant at the 0.05 level.

CPP-ACP: Casein phosphopeptide amorphous calcium phosphate

with $\mathrm{F}+$ laser significantly different the other groups $(P<0.05)$.

\section{DISCUSSION}

Despite advances in orthodontic materials and techniques, enamel demineralization around orthodontic appliances known as WSL remains a serious clinical problem, especially in patients with poor oral hygiene. WSLs develop due to long-term accumulation of bacterial plaque, which causes acidic dissolution of enamel. ${ }^{[15]}$

Evidence shows that the prevalence of decalcification in orthodontic patients varies from 50 to $95 \% .{ }^{[3,4]} \mathrm{O}^{\prime}$ Reilly and Featherstone ${ }^{[24]}$ showed that demineralization around orthodontic brackets may occur within 1 month in patients who use fluoridated toothpaste twice a day. High incidence and fast initiation of WSLs necessitate the use of preventive measures.

Aside from visual examination, which is the most commonly used technique in clinical examination for detection of WSLs, other methods are available for quantification and comparison of enamel demineralization including microhardness measurement, microradiography, polarized light microscopy, QLF, confocal microscopy, and laser fluorescence. ${ }^{[25]}$ Since enamel hardness is affected by its mineral content, microhardness test is extensively performed in vitro to assess enamel demineralization. The previous studies showed that microhardness test is a reliable, reproducible, and quantitative method for the assessment of demineralization. ${ }^{[26]}$ Of methods used for measurement of microhardness, the Knoop test has the lowest rate of measurement errors $(<5 \%)$. Moreover, evidence shows that a linear correlation exists between the enamel KHN and mineral content of the enamel ${ }^{[27]}$ such that correlation coefficient of $91 \%$ has been reported between hardness test and volume percentage of minerals. ${ }^{[26]}$ Thus, Knoop microindentation test was performed

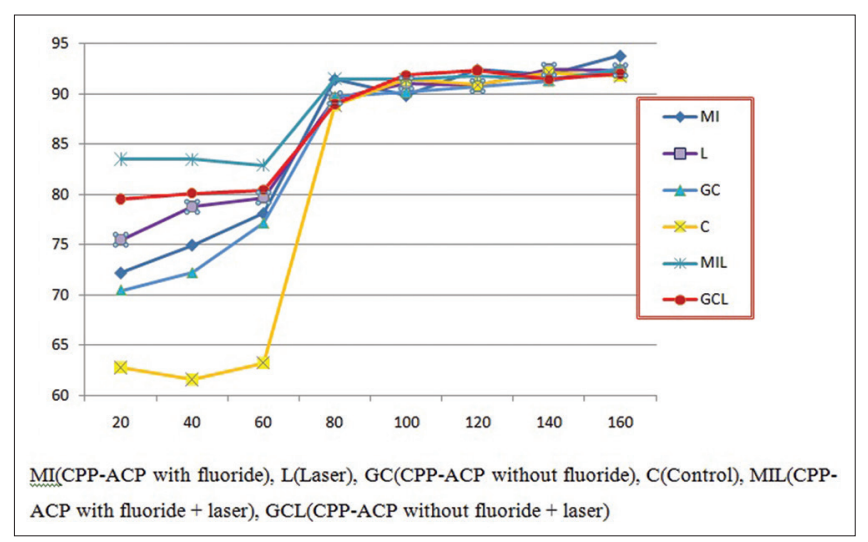

Figure 1: Comparison of volume of different groups at different depths

in our study for quantitative measurement of enamel demineralization.

To determine the hardness profile, hardness must be measured at specific distances from the external enamel surface. In previous studies, indentation has been performed at different distances from the surface. ${ }^{[27-30]}$ In the current study, the first indentation was made at $20 \mu$ distance from the surface and continued to $160 \mu$ depth. The reason behind selection of these distances was prevention of surface cracks, which occur if the indentation is made close to the surface and compromise accurate measurement. In addition, by keeping $10 \mu$ distances, risk of super positioning of indenter exists while greater distances complicate the detection of small changes of hardness at different depths of the enamel. ${ }^{[27]}$

In the current study, the mean hardness, volume percentage of mineral content, and relative mineral loss $(\Delta \mathrm{Z})$ in different groups were analyzed using one-way ANOVA and post hoc Tukey's test.

CPP-ACP is a natural derivative of milk and due to its high solubility, it can hydrolyze into apatite in the oral environment, making it a primary candidate for remineralization therapy. ${ }^{[29]}$

Evidence shows that CPP-ACP products prevent enamel demineralization and enhance remineralization in vitro and in vivo. ${ }^{[31]}$

CPP-ACP has been proved to have anti cariogenic activity in human studies ${ }^{[0,32]}$ although some studies suggest that the addition of CPP-ACP has no significant advantage over fluoride toothpaste. ${ }^{[33,34]}$ The evidence for the effectiveness of CPP-ACPF applications on the reduction of DWLs once orthodontic appliances have been removed is equivocal. Two studies found a 


\begin{tabular}{|c|c|c|c|}
\hline Group (A) & Group (B) & $\begin{array}{c}\text { Mean } \\
\text { difference } \\
(A-B)\end{array}$ & Significant \\
\hline \multirow[t]{5}{*}{ Control } & $\begin{array}{l}\text { CPP-ACP without } \\
\text { fluoride }\end{array}$ & $524.39^{*}$ & 0.000 \\
\hline & CPP-ACP with fluoride & $634.12^{*}$ & 0.000 \\
\hline & Laser & $766.62^{*}$ & 0.000 \\
\hline & $\begin{array}{l}\text { CPP-ACP without } \\
\text { fluoride + laser }\end{array}$ & $836.15^{*}$ & 0.000 \\
\hline & $\begin{array}{l}\text { CPP-ACP with } \\
\text { fluoride + laser }\end{array}$ & $1001.76^{*}$ & 0.000 \\
\hline \multirow{5}{*}{$\begin{array}{l}\text { CPP-ACP } \\
\text { without } \\
\text { fluoride }\end{array}$} & Control & $-524.39^{*}$ & 0.000 \\
\hline & CPP-ACP with fluoride & 109.73 & 0.339 \\
\hline & Laser & $242.23^{*}$ & 0.001 \\
\hline & $\begin{array}{l}\text { CPP-ACP without } \\
\text { fluoride + laser }\end{array}$ & $311.76^{*}$ & 0.000 \\
\hline & $\begin{array}{l}\text { CPP-ACP with } \\
\text { fluoride + laser }\end{array}$ & $477.38^{*}$ & 0.000 \\
\hline \multirow{5}{*}{$\begin{array}{l}\text { CPP-ACP } \\
\text { with fluoride }\end{array}$} & Control & $-634.12^{*}$ & 0.000 \\
\hline & $\begin{array}{l}\text { CPP-ACP without } \\
\text { fluoride }\end{array}$ & -109.73 & 0.339 \\
\hline & Laser & 132.49 & 0.154 \\
\hline & $\begin{array}{l}\text { CPP-ACP without } \\
\text { fluoride + laser }\end{array}$ & $202.03^{*}$ & 0.001 \\
\hline & $\begin{array}{l}\text { CPP-ACP with } \\
\text { fluoride + laser }\end{array}$ & $367.64^{*}$ & 0.000 \\
\hline \multirow[t]{5}{*}{ Laser } & Control & $-766.62^{*}$ & 0.000 \\
\hline & $\begin{array}{l}\text { CPP-ACP without } \\
\text { fluoride }\end{array}$ & $-242.23^{*}$ & 0.001 \\
\hline & CPP-ACP with fluoride & -132.64 & 0.154 \\
\hline & $\begin{array}{l}\text { CPP-ACP without } \\
\text { fluoride + laser }\end{array}$ & 69.53 & 0.794 \\
\hline & $\begin{array}{l}\text { CPP-ACP with } \\
\text { fluoride + laser }\end{array}$ & $235.14^{*}$ & 0.001 \\
\hline \multirow{5}{*}{$\begin{array}{l}\text { CPP-ACP } \\
\text { without } \\
\text { fluoride } \\
+ \text { laser }\end{array}$} & Control & $-836.15^{\star}$ & 0.000 \\
\hline & $\begin{array}{l}\text { CPP-ACP without } \\
\text { fluoride }\end{array}$ & $-311.76^{*}$ & 0.000 \\
\hline & CPP-ACP with fluoride & $-202.03^{*}$ & 0.001 \\
\hline & Laser & -69.53 & 0.794 \\
\hline & $\begin{array}{l}\text { CPP-ACP with } \\
\text { fluoride + laser }\end{array}$ & $165.62^{*}$ & 0.001 \\
\hline \multirow{5}{*}{$\begin{array}{l}\text { CPP-ACP } \\
\text { with fluoride } \\
+ \text { laser }\end{array}$} & Control & $-1001.76^{*}$ & 0.000 \\
\hline & $\begin{array}{l}\text { CPP-ACP without } \\
\text { fluoride }\end{array}$ & $-477.38^{\star}$ & 0.000 \\
\hline & CPP-ACP with fluoride & $-367.64^{*}$ & 0.000 \\
\hline & Laser & $-235.14^{*}$ & 0.001 \\
\hline & $\begin{array}{l}\text { CPP-ACP without } \\
\text { fluoride + laser }\end{array}$ & $-165.62^{*}$ & 0.001 \\
\hline
\end{tabular}

${ }^{*}$ The mean difference is significant at the 0.05 level. CPP-ACP: Casein phosphopeptide amorphous calcium phosphate

positive effect of using a CPP-ACP containing cream, in addition to fluoride, ${ }^{[35,36]}$ and three studies found a limited effect; ${ }^{[38-40]}$ therefore, further work in this area is required before a definitive answer is found. The difference between our results and the mentioned studies could be due to fact that, our study was a laboratory study while, those studies were performed in vivo.
In the current study, mineral loss in CPP-ACP with fluoride and without fluoride groups was significantly less than that in the control group $(P<0.0001)$. This indicates the positive efficacy of these materials for prevention of enamel demineralization. In addition, demineralization in CPP-ACP with fluoride group containing 900 ppm fluoride was less than that in the CPP-ACP without fluoride group; although this difference was not statistically significant. These results were in agreement with those of $\mathrm{Wu}$ et al. ${ }^{[15]}$ Iijima et al. ${ }^{[11]}$ and Elsayad et al..$^{[41]}$ which showed the greater efficacy of combination of CPP-ACP and fluoride for the prevention of enamel demineralization.

Kumar et al. ${ }^{[41]}$ compared the effect of CPP-ACP with fluoridated and nonfluoridated toothpastes and concluded that combination of CPP-ACP and fluoride was more effective than toothpastes for remineralization of WSLs. Their results were in agreement with ours regarding the optimal efficacy of CPP-ACP with fluoride (MI Paste Plus). Jayarajan et al. ${ }^{[14]}$ compared the efficacy of MI Paste Plus, $\mathrm{CPP}-\mathrm{ACP}$, and artificial saliva and concluded that MI Paste Plus was more effective than other groups due to the presence of fluoride in its composition; their study was somehow similar to our study regarding the materials tested and the results obtained. In our study, remineralization in CPP-ACP with fluoride and without fluoride groups was higher than that in the control group, and CPP-ACP with fluoride group showed slightly higher remineralization than CPP-ACP without fluoride group such that mineral loss at the first three depths was $68 \%$ in the control group, $36 \%$ in CPP-ACP without fluoride group and $32 \%$ in CPP-ACP with fluoride group. One advantage of CPP-ACP compared to fluoride is that CPP-ACP does not cause fluorosis. Thus, application of CPP-ACP alone or in combination with fluoride may decrease the amount of fluoride and lower the risk of fluorosis. ${ }^{[42]}$

Use of lasers for caries prevention has been an interesting topic of research in the recent years. Laser irradiation of teeth causes reactions between laser light and biologic materials in tooth structure. If laser light is absorbed by the enamel, its energy is converted to heat; these thermal effects cause chemical and microstructural changes in the enamel and increase its resistance to acid attacks. In demineralization tests, heating the enamel to $300^{\circ}-400^{\circ} \mathrm{C}$ decreases its relative solubility and the depth of lesions. Several theories have tried to explain the reduction in acidic dissolution of enamel following heating. In addition to decreased 
permeability of enamel following laser irradiation, release of bonded carbonate following enamel heating is a more acceptable theory. A direct correlation exists between carbonate loss following laser irradiation and decreased acidic dissolution of enamel. Moreover, the amount of hydroxide and pyrophosphate also increases following laser therapy. ${ }^{[43]}$

The ability of different wavelengths of erbium laser (erbium:yttrium-scandium-gallium-garnet, Er:YAG) for increasing the enamel resistance to acids has been previously evaluated

Liu et al..$^{[22]}$ de Andrade et al. ${ }^{[44]}$ and Apel et al. ${ }^{[45]}$ evaluated the effect of Er:YAG laser on enamel resistance to caries and indicated increased resistance of enamel to acids following subablative laser irradiation, which was in accord with our results. However, Apel et al. ${ }^{[45]}$ stated that prevention of unwanted ablation of enamel is difficult and cannot be achieved with the currently available lasers and wavelengths.

Nair et al. ${ }^{[46]}$ compared the efficacy of remineralizing agents in combination with Er:YAG laser for prevention of caries and reported the highest release of calcium ions in CPP-ACP group combined with laser. Their results were in line with ours. They used spectrometry for the assessment of demineralization while we used microhardness test as a standard and reproducible technique with less than $5 \%$ error rate. Yassaei et al. ${ }^{[47]}$ compared the efficacy of combined effects of Er:YAG laser and MI Paste plus on the inhibition of enamel demineralization. In the aforementioned three studies, laser irradiation combined with topical application of remineralizing agents had a greater efficacy for prevention of enamel demineralization, which was in agreement with the results of the current study showing the least demineralization in CPP-ACP with fluoride + laser and CPP-ACP without fluoride + laser groups.

\section{CONCLUSION}

Based on these results, Er:YAG laser was able to decrease demineralization and was a potential alternative to preventive dentistry and was more effective when combined with CPP-ACP products

\section{Suggestions}

In vitro studies have limitations in simulation of oral environment. Thus, the effect of these products on WSLs should also be evaluated in clinical studies.
Financial support and sponsorship

Nil.

\section{Conflicts of interest}

There are no conflicts of interest.

\section{REFERENCES}

1. Sudjalim TR, Woods MG, Manton DJ. Prevention of white spot lesions in orthodontic practice: A contemporary review. Aust Dent J 2006;51:284-9.

2. Ogaard B. Prevalence of white spot lesions in 19-year-olds: A study on untreated and orthodontically treated persons 5 years after treatment. Am J Orthod Dentofacial Orthop 1989;96:423-7.

3. Gorelick L, Geiger AM, Gwinnett AJ. Incidence of white spot formation after bonding and banding. Am J Orthod 1982;81:93-8.

4. Lovrov S, Hertrich K, Hirschfelder U. Enamel demineralization during fixed orthodontic treatment - Incidence and correlation to various oral-hygiene parameters. J Orofac Orthop 2007;68:353-63.

5. Reynolds EC. Remineralization of enamel subsurface lesions by casein phosphopeptide-stabilized calcium phosphate solutions. J Dent Res 1997;76:1587-95.

6. Rose RK. Binding characteristics of Streptococcus mutans for calcium and casein phosphopeptide. Caries Res 2000;34:427-31.

7. Reynolds EC. The role of phosphopeptides in caries prevention. Dent Perspect 1999;3:6-7.

8. Reynolds EC. Calcium phosphate-based remineralization systems: Scientific evidence? Aust Dent J 2008;53:268-73.

9. Reynolds EC, Cai F, Cochrane NJ, Shen P, Walker GD, Morgan MV, et al. Fluoride and casein phosphopeptide-amorphous calcium phosphate. J Dent Res 2008;87:344-8.

10. Uysal T, Amasyali M, Koyuturk AE, Sagdic D. Efficiency of amorphous calcium phosphate-containing orthodontic composite and resin modified glass ionomer on demineralization evaluated by a new laser fluorescence device. Eur J Dent 2009;3:127-34.

11. Iijima Y, Cai F, Shen P, Walker G, Reynolds C, Reynolds EC, et al. Acid resistance of enamel subsurface lesions remineralized by a sugar-free chewing gum containing casein phosphopeptide-amorphous calcium phosphate. Caries Res 2004;38:551-6.

12. Cochrane NJ, Saranathan S, Cai F, Cross KJ, Reynolds EC. Enamel subsurface lesion remineralisation with casein phosphopeptide stabilised solutions of calcium, phosphate and fluoride. Caries Res 2008;42:88-97.

13. Patil N, Choudhari S, Kulkarni S, Joshi SR. Comparative evaluation of remineralizing potential of three agents on artificially demineralized human enamel: An in vitro study. J Conserv Dent 2013;16:116-20.

14. Jayarajan J, Janardhanam P, Jayakumar P. Efficacy of CPP-ACP and CPP-ACPF on enamel remineralization - An in vitro study using scanning electron microscope and DIAGNOdent. Indian J Dent Res 2011;22:77-82.

15. Wu G, Liu X, Hou Y. Analysis of the effect of CPP-ACP tooth mousse on enamel remineralization by circularly polarized images. Angle Orthod 2010;80:933-8.

16. Hsu CY, Jordan TH, Dederich DN, Wefel JS. Effects of low-energy $\mathrm{CO} 2$ laser irradiation and the organic matrix on inhibition of enamel demineralization. J Dent Res 2000;79:1725-30.

17. Mohan AG, Ebenezar AV, Ghani MF, Martina L, Narayanan A, Mony B, et al. Surface and mineral changes of enamel with different remineralizing agents in conjunction with carbon-dioxide laser. Eur J Dent 2014;8:118-23.

18. Poosti M, Ahrari F, Moosavi H, Najjaran H. The effect of fractional $\mathrm{CO} 2$ laser irradiation on remineralization of enamel white spot lesions. Lasers Med Sci 2014;29:1349-55.

19. Bevilácqua FM, Zezell DM, Magnani R, da Ana PA, Eduardo Cde P. Fluoride uptake and acid resistance of enamel irradiated with Er: YAG laser. Lasers Med Sci 2008;23:141-7.

20. de Freitas PM, Rapozo-Hilo M, Eduardo Cde P, Featherstone JD. In vitro evaluation of erbium, chromium:yttrium-scandium-gallium-garnet laser-treated enamel demineralization. Lasers Med Sci 2010;25:165-70.

21. Geraldo-Martins VR, Lepri CP, Palma-Dibb RG. Influence of Er, Cr:YSGG laser irradiation on enamel caries prevention. Lasers Med 
Yassaei, et al.: Efficacy of Er:YAG and CPP-ACP $\pm F$ on white spot

Sci 2013;28:33-9.

22. Liu JF, Liu Y, Stephen HC. Optimal Er: YAG laser energy for preventing enamel demineralization. J Dent 2006;34:62-6.

23. Featherstone JD, ten Cate JM, Shariati M, Arends J. Comparison of artificial caries-like lesions by quantitative microradiography and microhardness profiles. Caries Res 1983;17:385-91.

24. O'Reilly MM, Featherstone JD. Demineralization and remineralization around orthodontic appliances: An in vivo study. Am J Orthod Dentofacial Orthop 1987;92:33-40.

25. Boersma JG, van der Veen MH, Lagerweij MD, Bokhout B, Prahl-Andersen B. Caries prevalence measured with QLF after treatment with fixed orthodontic appliances: Influencing factors. Caries Res 2005;39:41-7.

26. Knoop F, Peters CG, Emersoon WB. A sensitive pyramidal diamond tool for indentation measurements. J Res Natl Bur Stand 1939;23:39.

27. Purdell-Lewis DJ, Groeneveld A, Arends J. Microhardness and densitometric measurements of the effect of $4 \%$ SnF2 solution on artificial white spot lesions. Caries Res 1976;10:216-26.

28. Paes Leme AF, Tabchoury CP, Zero DT, Cury JA. Effect of fluoridated dentifrice and acidulated phosphate fluoride application on early artificial carious lesions. Am J Dent 2003;16:91-5.

29. Delbem AC, Cury JA. Effect of application time of APF and NaF gels on microhardness and fluoride uptake of in vitro enamel caries. Am J Dent 2002;15:169-72.

30. Chedid SJ, Cury JA. Effect of $0.02 \% \mathrm{NaF}$ solution on enamel demineralization and fluoride uptake by deciduous teeth in vitro. Pesqui Odontol Bras 2004;18:18-22.

31. Brochner A, Christensen C, Kristensen B, Traneus S, Karlsson L, Sonnesen L, et al. Treatment of post orthodontic white spot lesions with casein phosphopeptide-stablished amorphous calcium phosphate. Clin Oral Investig 2010;10:20-8.

32. Reynolds EC. Anticariogenic complexes of amorphous calcium phosphate stabilized by casein phosphopeptides: A review. Spec Care Dentist 1998;18:8-16.

33. Rao SK, Bhat GS, Aradhya S, Devi A, Bhat M. Study of the efficacy of toothpaste containing casein phosphopeptide in the prevention of dental caries: A randomized controlled trial in 12- to 15-year-old high caries risk children in Bangalore, India. Caries Res 2009;43:430-5.

34. Sitthisettapong T, Phantumvanit P, Huebner C, Derouen T. Effect of CPP-ACP paste on dental caries in primary teeth: A randomized trial. J Dent Res 2012;91:847-52.

35. Andersson A, Sköld-Larsson K, Hallgren A, Petersson LG, Twetman S. Effect of a dental cream containing amorphous cream phosphate complexes on white spot lesion regression assessed by laser fluorescence. Oral Health Prev Dent 2007;5:229-33.

36. Bailey DL, Adams GG, Tsao CE, Hyslop A, Escobar K, Manton DJ, et al. Regression of post-orthodontic lesions by a remineralizing cream. J Dent Res 2009;88:1148-53.

37. Beerens MW, van der Veen MH, van Beek H, ten Cate JM. Effects of casein phosphopeptide amorphous calcium fluoride phosphate paste on white spot lesions and dental plaque after orthodontic treatment: A 3-month follow-up. Eur J Oral Sci 2010;118:610-7.

38. Bröchner A, Christensen C, Kristensen B, Tranæus S, Karlsson L, Sonnesen L, et al. Treatment of post-orthodontic white spot lesions with casein phosphopeptide-stabilised amorphous calcium phosphate. Clin Oral Investig 2011;15:369-73.

39. Huang GJ, Roloff-Chiang B, Mills BE, Shalchi S, Spiekerman C, Korpak AM, et al. Effectiveness of MI paste plus and PreviDent fluoride varnish for treatment of white spot lesions: A randomized controlled trial. Am J Orthod Dentofacial Orthop 2013;143:31-41.

40. Elsayad I, Sakr A, Badr Y. Combining casein phosphopeptide-amorphous calcium phosphate with fluoride: Synergistic remineralization potential of artificially demineralized enamel or not? J Biomed Opt 2009;14:044039.

41. Kumar VL, Itthagarun A, King NM. The effect of casein phosphopeptide-amorphous calcium phosphate on remineralization of artificial caries-like lesions: An in vitro study. Aust Dent J 2008;53:34-40.

42. Tung MS, Eichmiller FC. Dental applications of amorphous calcium phosphates. J Clin Dent 1999;10:1-6.

43. Nammour S, Renneboog-Squilbin C, Nyssen-Behets C. Increased resistance to artificial caries-like lesions in dentin treated with $\mathrm{CO} 2$ laser. Caries Res 1992;26:170-5.

44. de Andrade LE, Pelino JE, Lizarelli RF, Bagnato VS, de Oliveira OB. Caries resistance of lased human enamel with Er:YAG laser morphological and ratio Ca/P analysis. Laser Phys 2007;4:157-62.

45. Apel C, Birker L, Meister J, Weiss C, Gutknecht N. The caries-preventive potential of subablative Er:YAG and Er:YSGG laser radiation in an intraoral model: A pilot study. Photomed Laser Surg 2004;22:312-7.

46. Nair AS, Kumar RK, Philip ST, Ahameed SS, Punnathara S, Peter J, et al. A comparative analysis of caries inhibitory effect of remineralizing agents on human enamel treated with Er:YAG laser: An in vitro atomic emission spectrometry analysis. J Clin Diagn Res 2016;10:ZC10-3.

47. Yassaei S, Shahraki N, Aghili H, Davari A. Combined effects of Er: YAG laser and casein phosphopeptide-amorphous calcium phosphate on the inhibition of enamel demineralization: An in vitro study. Dent Res J (Isfahan) 2014;11:193-8. 